\title{
Ultra-Structural Characteristics of Aloe vera-Based Nanofibers as MRSA-Phage Nanocarriers
}

\author{
Hiva Hashemi ${ }^{1}$, Golnar Rahimzadeh ${ }^{2}$ (D), Majid Saeedi ${ }^{3}$ (D), Fatemeh Ghadami ${ }^{4}$, Adele Rafati ${ }^{1,5}$ (D), \\ Pooria Gill 1,6,*iD
}

1 Department of Medical Nanotechnology, School of Advanced Technologies in Medicine, Mazandaran University of Medical Sciences, Sari, Iran

2 Pediatric Infectious Diseases Research Center, Mazandaran University of Medical Sciences, Sari, Iran

3 Department of Pharmaceutics, School of Pharmacy, Mazandaran University of Medical Sciences, Sari, Iran

4 Central Research Laboratory, Vice-Chancellor of Research and Technology, Mazandaran University of Medical Sciences, Sari, Iran

5 Research Center for Plant and Livestock Products, Mazandaran University of Medical Sciences, Sari, Iran

6 Research Center of Immunogenetics, Mazandaran University of Medical Sciences, Sari, Iran

* Correspondence: Pooriagill@yahoo.com, p.gill@mazums.ac.ir (P.G.);

Received: 5.04.2021; Revised: 15.05.2021; Accepted: 20.05.2021; Published: 18.06.2021

\begin{abstract}
This study investigates the mechanical, thermodynamic, and morphological changes and surface topography of Aloe vera (AV)-based nanofibers as the nanocarriers of methicillin-resistant Staphylococcus aureus (MRSA). After making the AV-based solutions, the nanofibers were made by electrospinning device and the topography and roughness coefficient of the nanofibers were obtained by atomic force microscopy (AFM). A tensile test was used to evaluate the mechanical properties of the nanofibers and simultaneous thermal analysis (STA) was used for thermal testing. The results of AFM showed nanofiber deformation in the combination of $\mathrm{AV}$-phages. It was observed in the mechanical test results that with the addition of phage to AV-nanofibers, although the elastic module decreased, the elongation percentage increased, with high resistance to stretching. Also, the thermal analysis results were such that the addition of phage to AV-nanofibers increased the thermal stability of the nanofibers. The addition of MRSA phages to the Aloe vera nanofibers was increased thermal stability and the percentage of elongation of the nanofibers. The combination of AV-phage nanofibers creates a new carrying capacity at the nanofiber level to be a candidate for wound dressing as a therapeutic agent.
\end{abstract}

Keywords: Aloe vera (AV); nanofiber; MRSA phage; nanocarrier.

(C) 2021 by the authors. This article is an open-access article distributed under the terms and conditions of the Creative Commons Attribution (CC BY) license (https://creativecommons.org/licenses/by/4.0/).

\section{Introduction}

In recent years, interest in the study of nanofibers has increased significantly. Nanofibers with a diameter at the nanometer scale are called nanofibers. They are considered candidates for antibacterial coatings due to their high surface-to-volume ratio, excellent mechanical properties, high flexibility, and ability to absorb secretions. And they have many applications in various fields of medicine, health, and industry [1-3]. For example, in the drug delivery, polylactic acid/collagen nanofibers containing gentamicin antibiotics were able to deliver sustained and controlled drug delivery in treating bacterial infections [4]. In the field of tissue engineering, Lilex et al., in 2013, made nanofiber scaffolds of chitosan and 
hydroxyapatite with genipin, which they use in bone cells to produce and support osteoblast cell proliferation [5].

Nanofibers are made from various synthetic and natural polymers and biocompatible and biodegradable polymers such as chitosan, polyvinyl alcohol, gelatin, and polycaprolactone [6,7]. Polyvinyl alcohol is one of the water-soluble synthetic polymers. This polymer is nontoxic and biocompatible. It has a high resistance to heat, and this polymer's structural and mechanical properties make it a good candidate for the production of nanofibers [8-10]. Nanofiber technology has been considered for several centuries, but its inventions and related products depended on developing the electrospinning method because it is one of the most common and practical methods of making nanofibers [1,11].

Most recently, the use of plant extracts and gels to make nanofibers by electrospinning has received much attention because plants such as Aloe vera (AV) have antibacterial, antifungal, and antiviral activity due to their compounds such as folic acid, vitamins, and amino acids [12,13]. For example, Aloe vera gel can be used in various concentrations as an antibacterial agent against $P$. aeruginosa [14]. Another treatment for this gel is wound healing. By adding collagen to this substance, the wound contractility increases and the wound heals faster [15]. Also, Aloe vera nanocellulose was used as an antibacterial agent against microorganisms and found that the antibacterial effects of Aloe vera nanocellulose were much stronger than non-nano Aloe vera [16].

Bacteriophages are obligate intracellular parasites that can kill bacteria without adversely affecting human and animal cells [17]. Phages have many applications due to their antibacterial properties and are sometimes fixed on surfaces by covalent bonding to have an antibacterial effect [18].

Atomic force microscopy is used to study nanofibers' surface topography and morphology and mechanical and structural properties. This microscope gives a lot of information about the surface of nanofibers, such as roughness, porosity, and elevation [19,20]. The atomic force microscope (AFM), or scanning the force microscope (SFM), was invented in 1986 by Binnig, Quate, and Gerber. Atomic force microscopy (AFM) is becoming one of the most significant techniques among scanning probe microscopes (SPM) for examining surface forces at the nanometer scale. It also is an essential tool for studying the morphology and structural properties of the surface and can also provide much information about the interactions of biological materials on the surface of nanoparticles [21].

\section{Materials and Methods}

\subsection{Preparation of $A V$ gel solution.}

First, prepare Aloe vera leaves from Barbadensis species, Clean them, separate the middle gel, and put it in the homogenizer for $30 \mathrm{~min}$ to homogenize.

\subsection{Preparation of solutions for making nanofibers.}

To prepare AV-nanofibers solution, $9 \mathrm{ml}$ of aloe vera gel solution mixed with $1 \mathrm{~g}$ of polyvinyl alcohol powder (Sigma-Aldrich, Germany). Also, for preparing the solution of AVbased nanofibers contained MRSA phages, 1 gr of polyvinyl alcohol powder dissolved in $9 \mathrm{~mL}$ of AV gel solution and after cooling, $1 \mathrm{ml}$ of MRSA phages prepared previously according to Rahimzadeh et al. protocol [22] was added into the cooled mixture. 


\subsection{Fabrication of nanofibers using electrospinning technique.}

For the fabrication of nanofibers, a piece of aluminum foil was placed on the drum of the four-nozzle model ESY 20 electrospinning device, which acts as a fiber collector. Then, a certain amount of Aloe vera gel solutions were poured into two syringes and placed in the nozzle position. The electrospinning device was set at room temperature with a speed of 0.2 $\mathrm{ml} / \mathrm{h}$, a 15 to $17 \mathrm{kV}$ voltage, and a nozzle distance from the collector of $120 \mathrm{~mm}$.

\subsection{Atomic force microscopy of nanofibers.}

After placing the slide on the collector of the electrospinning device and forming a layer of nanofibers, we use the slide to AFM analyze the surface. To check the topography of the surface of the nanofibers, we photographed our nanofibers with JPK-AFM, with $150 \mathrm{HZ} 1 \mathrm{Gain}$, 0.0048 PGain, and 1.0V setpoint via a JPK Nano Wizard Control. The cantilever was the ACTA-10 probe model. Topographic images from samples 1 to 4 in the form of 3D and height (measured) and to scan range of $5 \times 5 \mu \mathrm{m}$ were prepared.

\subsection{Tensile test of nanofibers.}

To investigate the mechanical properties of nanofibers, we used the STM-5 tensile device. First, we cut the nanofibers in dimensions of $1 \times 4 \mathrm{~cm}$ and a thickness of $0.02 \mathrm{~mm}$, and then we placed them between the two clamps of the machine. The load cell used in this work was RO: $1.99112 \mathrm{Cap}: 6 \mathrm{Kg}$. It was performed at room temperature and at a speed of $5 \mathrm{~mm} / \mathrm{min}$. And ended after the nanofibers broke.

\subsection{Simoultaneusely thermal analysis of nanofibers.}

We used the BAHR Thermal analyze simultaneous thermal analysis device STA503 with DTA function device to investigate the thermal stability of nanofibers made. First, the nanofibers were prepared in equal weights and analyzed in a temperature program of 10-400 ${ }^{\circ} \mathrm{C}$ at a speed of $10{ }^{\circ} \mathrm{C}$ per minute and inside a platinum crucible.

\section{Results and Discussions}

\subsection{Roughness measurements of nanofibers.}

To investigate the topography and height changes at the surface of the fabricated nanofibers and the interactions between aloe vera and bacteriophage and both together in the fabrication of nanofibers, AV-based nanofibers were examined directly using an atomic force microscope. The micrographs obtained from AFM were in the scan range of $5 \times 5 \mu \mathrm{m}$ in the form of three-dimensional micrographs (Figure 1). There were significant changes in the morphology of the nanofibers and the placement of aloe vera and phage, both together in AVbased nanofibers.

\subsection{Mechanical strengths of nanofibers.}

The results of this test are in the form of the diagrams (Figure 2) and were obtained based on the force applied to the nanofiber until it ruptured. Parameters stress, elongation, and the elastic module were obtained for the nanofibers reported in Table 1. 


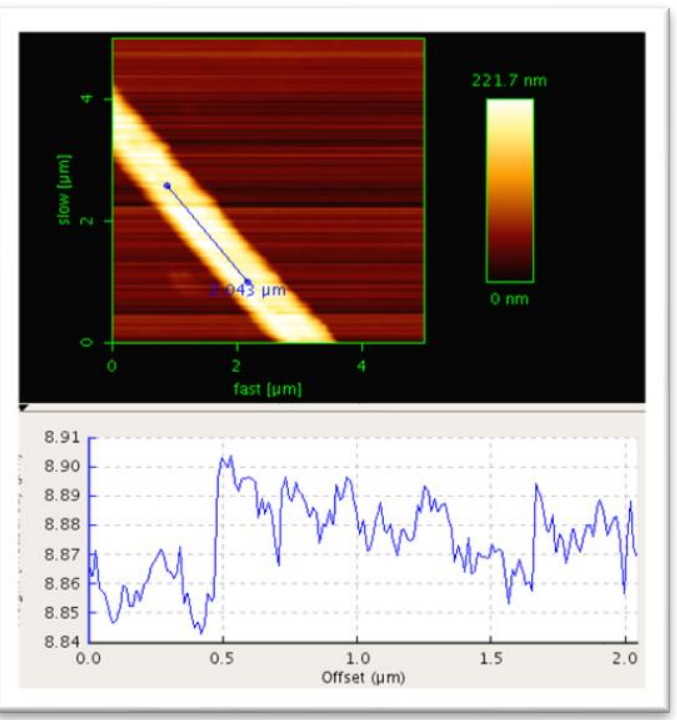

(a)

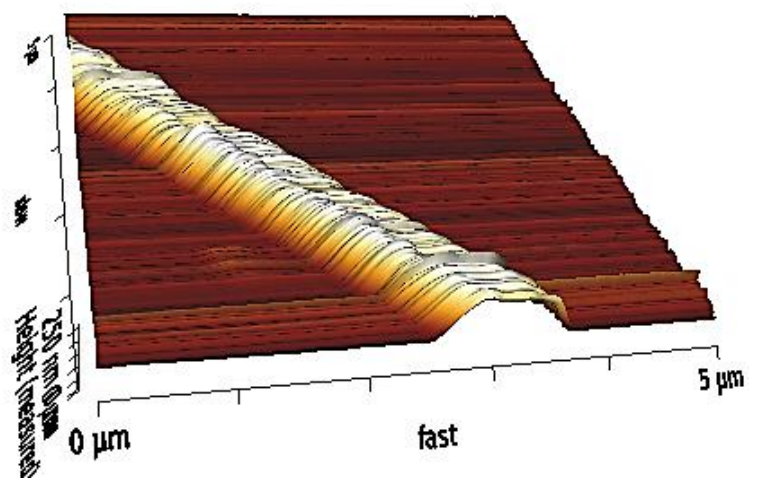

\begin{tabular}{|c|c|}
\hline $\begin{array}{c}\text { Roughness } \\
\text { mode }\end{array}$ & $\begin{array}{c}\text { Roughness } \\
\text { measurement }\end{array}$ \\
\hline $\mathrm{Ra}$ & $11.47 \mathrm{~nm}$ \\
\hline $\mathrm{Rq}$ & $13.92 \mathrm{~nm}$ \\
\hline $\mathrm{Rt}$ & $61.03 \mathrm{~nm}$ \\
\hline
\end{tabular}
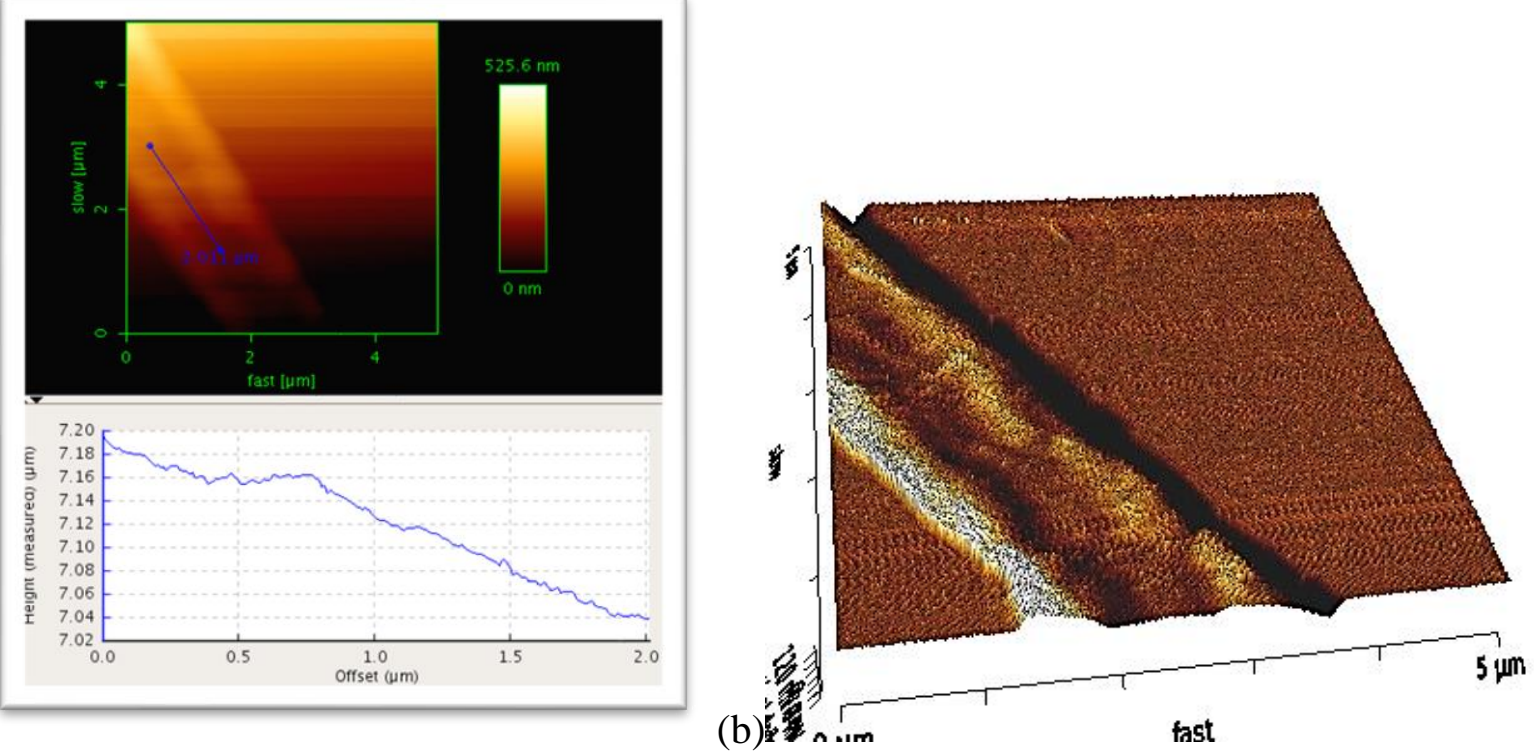

\begin{tabular}{|c|c|}
\hline $\begin{array}{c}\text { Roughness } \\
\text { mode }\end{array}$ & $\begin{array}{c}\text { Roughness } \\
\text { measurement }\end{array}$ \\
\hline $\mathrm{Ra}$ & $40.36 \mathrm{~nm}$ \\
\hline $\mathrm{Rq}$ & $45.96 \mathrm{~nm}$ \\
\hline $\mathrm{Rt}$ & $156.7 \mathrm{~nm}$ \\
\hline
\end{tabular}

Figure 1. Topography and roughnesses of AV-based nanofiber (a) and AV-phage nanofiber (b) in two- (left) and three dimensional (right) micrographs 


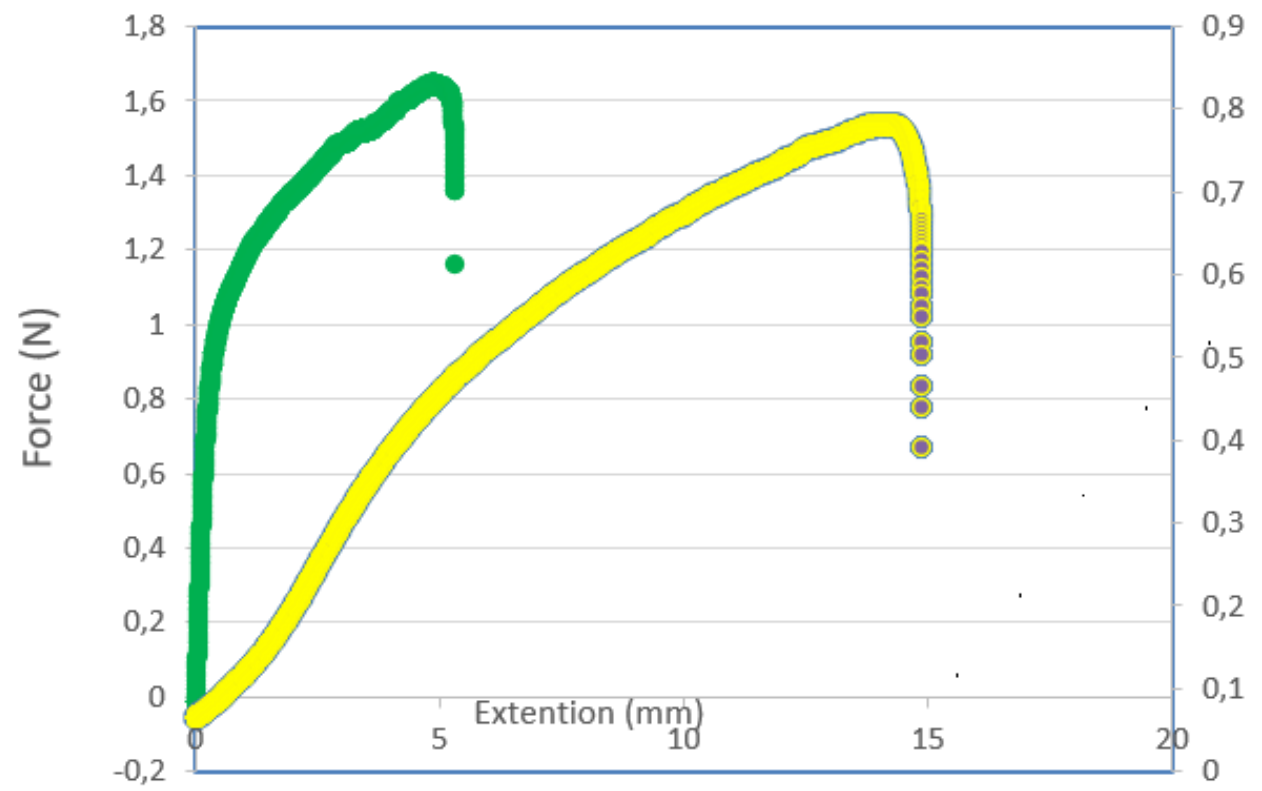

Figure 2. Comparison of graphs obtained from tensile test results for AV nanofibers (green curve) and AVPhage nanofibers (yellow curve)

Table 1. Comparison table of Stress, Elongation, and Elastic Module values for nanofibers

\begin{tabular}{c|c|c} 
& AV Nanofibers & AV-phage nanofibers \\
\hline Stress ( MPa) & 8.24 & 3.90 \\
\hline Elongation (\%) & 24.49 & 71.70 \\
\hline Elastic Module (MPa ) & 159.09 & 8.57
\end{tabular}

\subsection{Thermal analyses of nanofibers.}

The results of this test are in the form of graphs that can be seen in Figure 3, which show the parameters of temperature, enthalpy changes, and relative quantity of mass. Also, Table 2 compares these parameters for the nanofibers.

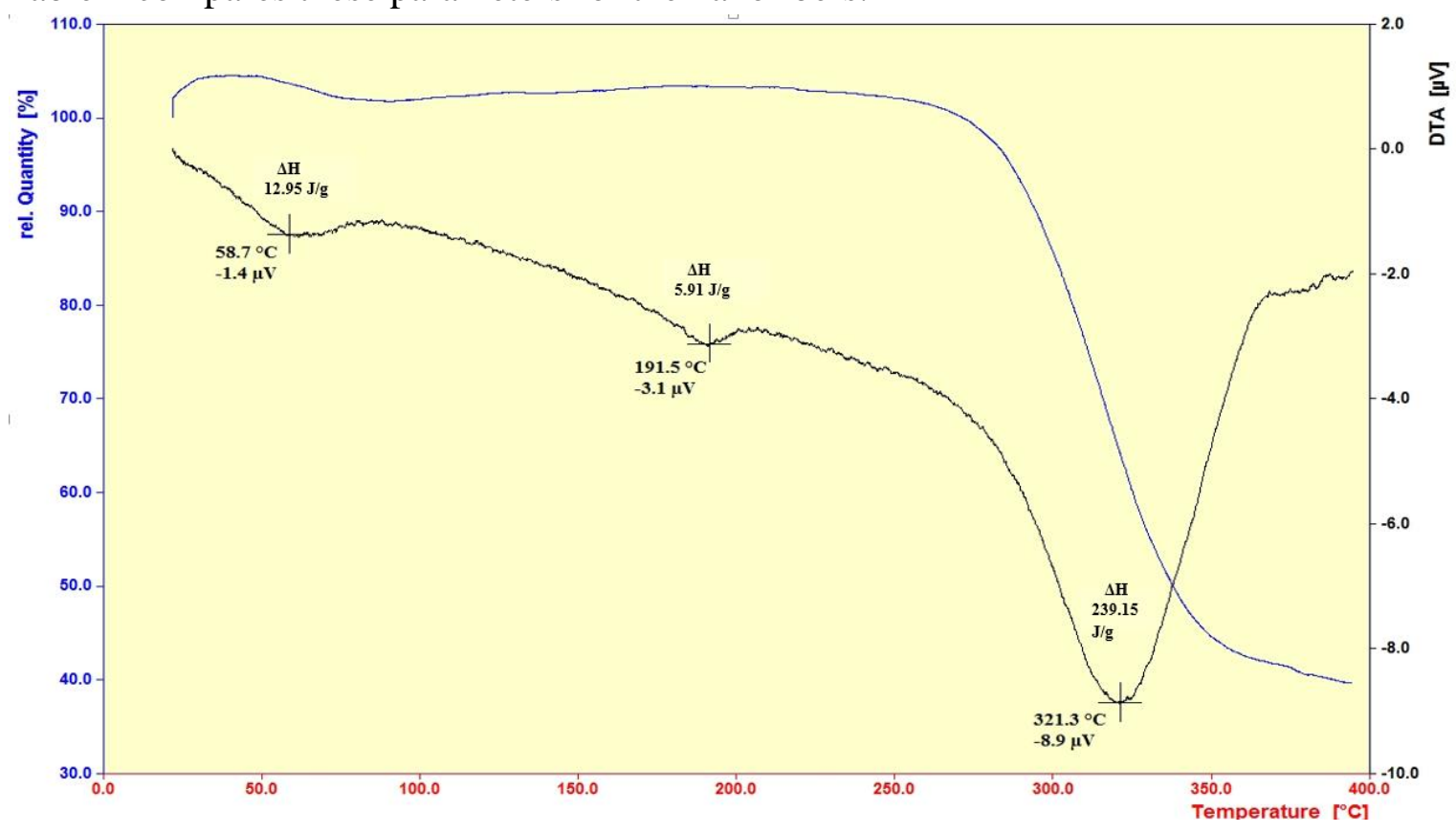

(a) 


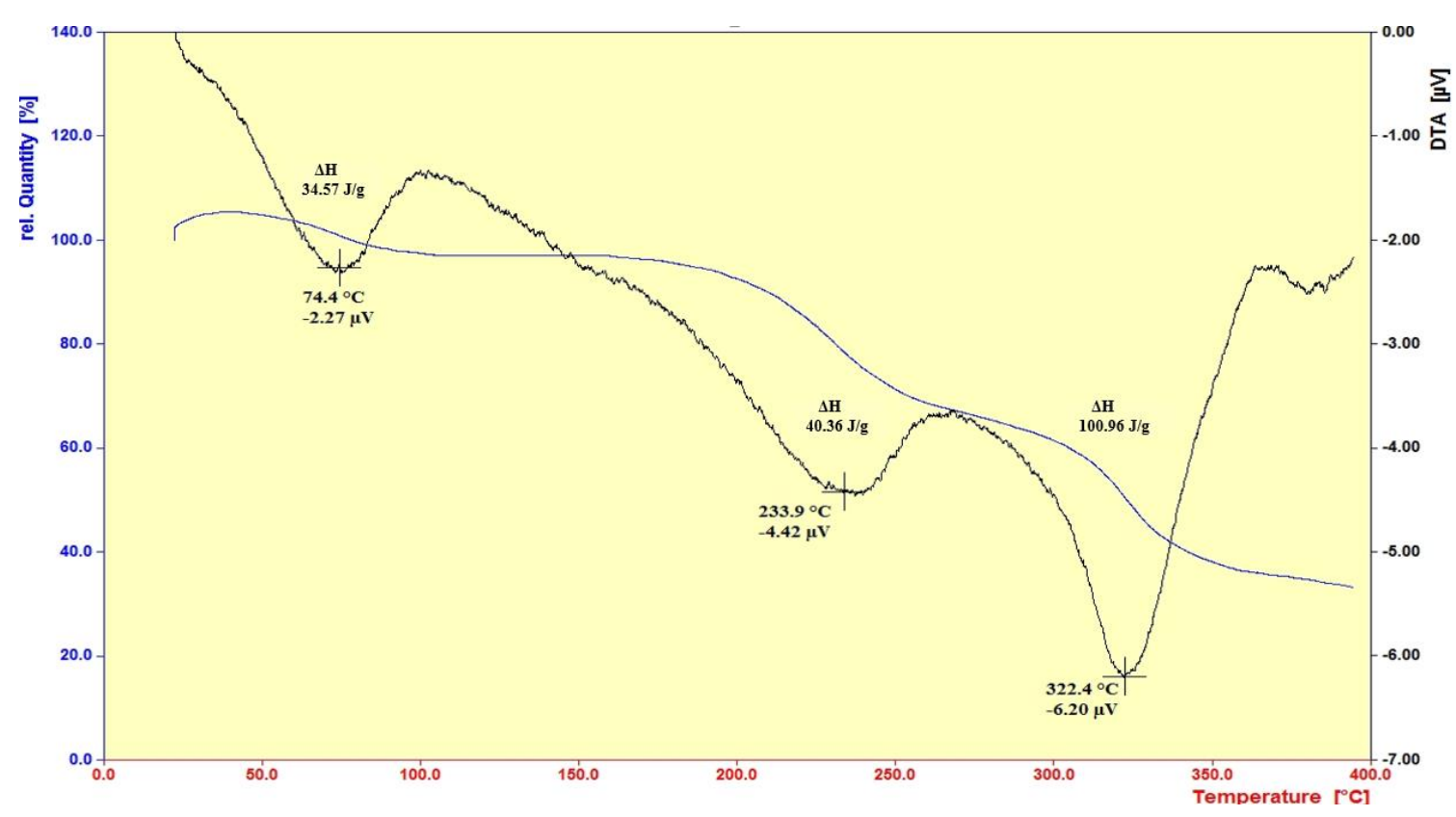

Figure 3. Simultaneously thermal analyses (differential thermal analysis and thermal gravity analysis) of AVnanofibers (a) and AV-phage nanofibers (b).

Table 2. Peak temperatures, $\Delta \mathrm{Hs}$, and relative quantity values of nanofibers

\begin{tabular}{c|c|c|c|c|c|c|c|c|c} 
& \multicolumn{3}{|c|}{ Temperature $\left({ }^{\circ} \mathbf{C}\right)$} & \multicolumn{3}{|c|}{$\mathbf{H}(\mathrm{J} / \mathrm{g})$} & \multicolumn{3}{c}{ Rel.Quantity ( \% ) } \\
\hline Nanofibers & $\begin{array}{c}\text { 1st } \\
\text { peak }\end{array}$ & $\begin{array}{c}\text { 2nd } \\
\text { peak }\end{array}$ & $\begin{array}{c}\text { 3rd } \\
\text { peak }\end{array}$ & $\begin{array}{c}\text { 1st } \\
\text { peak }\end{array}$ & $\begin{array}{c}\text { 2nd } \\
\text { peak }\end{array}$ & $\begin{array}{c}\text { 3rd } \\
\text { peak }\end{array}$ & $\begin{array}{c}\text { 1st } \\
\text { peak }\end{array}$ & $\begin{array}{c}\text { 2nd } \\
\text { peak }\end{array}$ & $\begin{array}{c}3 \text { rd } \\
\text { peak }\end{array}$ \\
\hline AV-nanofibers & 58.7 & 191.5 & 321.3 & 12.95 & 5.91 & 239.15 & 103.56 & 103.32 & 64.06 \\
\hline $\begin{array}{c}\text { AV-phage } \\
\text { nanofibers }\end{array}$ & 74.4 & 233.9 & 322.4 & 34.57 & 40.36 & 100.96 & 100.83 & 78.31 & 50.44
\end{tabular}

\subsection{Discussion.}

This study investigates the mechanical, thermodynamic, and morphological changes and surface topography of Aloe vera-based nanofibers after the addition of Aloe vera, bacteriophage, and Aloe vera-phage composition. To investigate the topography and roughness of the nanofibers made, we used AFM and evaluate the thermodynamic and mechanical properties of the nanofibers via STA and the tensile test method. In AFM micrographs, it was observed that the nanofibers were rotating overall, where phages were added to the nanofiber composition, folds can be seen on the surface of the nanofibers, they are visible in the form of cuts, folds on the surface of the nanofibers.

Although, when Aloe vera and phage were put together at the same time to make a composite nanofiber, the nanofiber deformed from a rotating and cylindrical state, creating a deep groove in the middle, which itself created a greater carrying capacity for the nanofiber. This carrying capacity can transport drugs in drug delivery, tissue engineering, or cell culture on nanofiber scaffolds. As Zamani et al. found in 2013, PLGA nanofiber scaffolds made by electrospinning in a cylindrical manner with a porous, rough surface enhance nerve cell growth compared to smooth nanofiber scaffolds [23,24].

Also, in the roughness results obtained from AFM, the average roughness (Ra), the root mean square (Rq or RMS), and the maximum height of the profile (Rt) of the nanofibers shows that the Aloe vera-based nanofibers were almost close to each other, but in the case of the Aloe vera-phage nanofibers it was increased more significantly due to the groove created. The groove mentioned in 3D images is also completely visible. In the studies of Scott, Soothill, and 
Urban, bacteriophage was covalently attached to the polymer surface, thus preserving the biological activity of the phages. But for this purpose, first, the surface of the polymer was chemically functionalized and then the phage was connected from its capsid head to the polymer substrate. However, we have shown in our work that non-covalent bonding can bind phage to nanofibers, and the presence of phage was visible in the AFM results [25-29].

Chlanda et al. made four types of nanofibers with different polymers and examined the surface topography of these nanofibers using an atomic force microscope. In one case, by adding hydroxyapatite (HAp) to polycaprolactone (PCL), they observed PCL/ HAp nanofiber diameter and the average roughness relative to PCL nanofiber increased. In the next case, hydroxyapatite and collage were added to Poly(l-lactide-co-caprolactone) (PLCL) and the PLCL / COL/ HAp nanofiber was fabricated by electrospinning. In this case, it was observed that the nanofiber diameter increased, but the average roughness decreased compared to PLCL nanofiber. Therefore, they concluded that collagen smoothes the surface of the nanofiber [29,31]; however, in this work, the addition of bacteriophage not only increased the average roughness but also created a greater carrying capacity. In the study by Philip et al., they made a combination of poly(methyl methacrylate) (PMMA) and poly(ethylene oxide) (PEO) nanofibers by electrospinning. Examining the Rq roughness using AFM, they found that $\mathrm{Rq}$ for the composite nanofiber was $26.6 \mathrm{~nm}$, but after removing polyethylene oxide from the composition, the Sq increased to $269.1 \mathrm{~nm}$, about 10 times. They concluded that removing PEO caused pores and porosity at the nanofiber surface, thus making it more useful [32].

In this study, in contrast, the addition of the MRSA phages to Aloe vera-based nanofibers increased the roughness. Comparing the 3D images of this nanofiber with the nanofibers did our work, it was observed that their nanofiber and the 1 to 3 samples of our nanofiber are rotary, but our sample 4 is mentioned for the same reason, i.e., the placement of phage and aloe vera, from the rotating state is deformed and a groove is formed in the middle of the nanofiber, which is quite visible in 3D images. However, in terms of roughness, the study of these researchers and our study showed almost similar results. In this way, in their work and we, after making a change in the initial nanofiber PVA- based, we saw an increase in roughness values several times [33]. In the results obtained from DTA, we see that by adding AV to Aloe vera-based nanofiber, there is no visible change in glass transition temperature, crystallization temperature, melting temperature, as well as enthalpy and relative quantity of mass, but with the addition of Phage and AV-Phage combination to PVA-based nanofibers, these parameters increase significantly. They show that bacteriophage has increased the stability and thermal resistance of nanofibers.

On the other hand, in the relative quantity of mass diagram, in the AV-nanofibers, mass loss was observed in only two points, but in AV-phage nanofibers, the mass changes were in 3 points which confirmed the presence of phage in the nanofiber. In general, it shows that with the presence of phage, the thermal stability of nanofibers is increased. At a higher temperature, the mass decreases, and this nanoparticle's addition causes more hydrogen bonds to be broken and more energy to be released. In 2014, Abdullah et al. combined PVA nanofibers with aloe vera and tested it as a polymer-drug carrier. The results of their heat test showed that adding aloe vera to PVA reduced the glass transition temperature and melting temperature; however, in this study, adding Aloe vera to PVA nanofibers did not change the glass temperature, but similarly, with the work, they observed a decrease in melting temperature.

Also, with the addition of phage to Aloe vera gel, the thermal stability of the nanofiber increased. In one study, polyurethane nanofibers were thermally evaluated before and after the 
incorporation of chitosan/polyethylene oxide. They observed that the glass transition temperature increased sharply by incorporating Cs / PEO into PU nanofibers [34]. They concluded that chitosan acts as a plasticizer and enhances the hydrophilic properties of nanofibers. Similar to their work, we also observed that the addition of phage and phage-aloe vera significantly increases the glass transition temperature, so it can be said that phage increases the hydrophilic properties of the polymer, and on the other hand, the enthalpy changes by adding phage and phage-aloe vera it also increases, indicating that more hydrogen bonds are broken. More energy content is released, proving the presence of phage in the nanofiber [35].

In the other study, with the production of polyvinyl alcohol and aloe vera nanofibers, it was observed that the glass transition temperature and melting temperature did not change much. Compared to our study, we did not see much change after adding aloe vera to polyvinyl alcohol, but with the addition of phage and phage-Aloe vera, we had a significant increase in these temperatures, which showed that phage bonds with the polymer and has thermal stability increased the nanofibers and created a more amorphous structure [36].

The tensile test results showed that by adding phage to the Aloe vera-based nanofibers, the elastic module was drastically reduced. Both AV and Phage had water-based compounds, that those compounds reduced the hardness of polymer-based nanofibers. Also, a significant increase in elongation of nanofibers indicated that the addition of phage to AV-nanofibers increased stability against stretching. Hence, with the addition of phage to Aloe vera, although the elastic module decreased significantly, the elongation percentage increased sharply. This phenomenon indicated the stability of nanofibers against elongation that was reported previously elsewhere [37]. In another study, hydrogel films were made from polyvinyl alcohol and aloe vera, and the mechanical properties of the films were investigated before and after the addition of aloe vera [38]. However, it was found that $30 \%$ gel content from Aloe vera, the elastic module and elongation increased, an increase in both parameters was also seen by adding MRSA phages to Aloe vera nanofibers [38].

\section{Conclusions}

This study aimed to investigate the mechanical, thermodynamic, and topographic properties of AV-based nanofibers and AV-MRSA phage nanofibers. The AFM results showed that the morphology of the nanofibers was rotational with the addition of AV and MRSA phage compared to AV-nanofibers; however, the addition of MRSA phage to AV-nanofibers caused the rotational deformation of the nanofibers to create a groove in the middle of the nanofiber. The groove created a new carrying capacity in the nanofibers and these nanocarriers can be used for antibacterial therapeutics. Also, with the addition of phage, either alone or in combination with Aloe vera, elongation is significantly increased, which means that the phages increased the resistance of the nanofibers to stretching. On the other hand, with the addition of phage to the Aloe vera gel, thermodynamic parameters such as the melting temperature and the enthalpy changes increased sharply, which seems to have increased the thermal stability of nanofibers for their using in wound dressing purposes.

\section{Funding}

This research was funded by the Vice-Chancellor of Research and Technology, Mazandaran University of Medical Sciences, grant number 5725. 


\section{Acknowledgments}

The authors thank Dr. Mohammad Ahanjan and Dr. Farahad Gholami for their collaborations using the Microbiology Laboratory in the Faculty of Medicine, Mazandaran University of Medical Sciences.

\section{Conflicts of Interest}

The authors declare no conflict of interest.

\section{References}

1. Gugulothu, D.; Barhoum, A.; Nerella, R.; Ajmer, R.; Bechelany, M. Fabrication of nanofibers: electrospinning and non-electrospinning techniques. In Handbook of Nanofibers; Barhoum, A., Bechelany, M., Makhlouf, A.S.H., Eds.; Springer International Publishing: Otto-Hausmann-Ring 101, D-42115 Wuppertal, Germany, 2019, 45-77, https://doi.org/10.1007/978-3-319-53655-2_6.

2. Khatri, Z.; Kim I-S.; Kim, S.H. Functional nanofibers: production and applications. J. Nanomater. 2016, 12, http://dx.doi.org/10.1155/2016/2195787.

3. Mohiti-Asli, M.; Loboa, E. Nanofibrous smart bandages for wound care. In Wound Healing Biomaterials; Ågren, M.S., Eds.; WoodHead Publishing Series in Biomaterials: Elsevier B.V., UK, 2016, 2, 483-499, https://doi.org/10.1016/B978-1-78242-456-7.00023-4.

4. Luraghi, A.; Peri, F.; Moroni, L. Electrospinning for drug delivery applications: A review. J. Control. Release 2021, https://doi.org/10.1016/j.jconrel.2021.03.033.

5. Lelkes, P.I.; Frohbergh, M. Electrospun mineralized chitosan nanofibers crosslinked with genipin for bone tissue engineering. US Patent No. 20130274892A1; 2013.

6. Keshvardoostchokami, M.; Majidi, S.S.; Huo, P.; Ramachandran, R.; Chen, M.; Liu, B. Electrospun nanofibers of natural and synthetic polymers as artificial extracellular matrix for tissue engineering. Nanomaterials (Basel) 2020, 11, 1-21, https://dx.doi.org/10.3390\%2Fnano11010021.

7. Subtirica, A-I.; Banciu, C.A.; Chivu, A.; Dinca, L-C. Nanofibres made from biocompatible and biodegradable polymers, with potential application as medical textiles. Industria Textila 2018, 69, 55-58, https://doi.org/10.35530/it.069.01.1502.

8. Puppi, D.; Chiellini, F. Biodegradable Polymers for Biomedical Additive Manufacturing. Appl. Mater. Today 2020, 20, https://doi.org/10.1016/j.apmt.2020.100700.

9. Teixeira, M.A.; Amorim, M.T.P.; Felgueiras, H.P. Poly(vinyl alcohol)-based nanofibrous electrospun scaffolds for tissue engineering applications. Polymers 2020, 12, 1-33, https://doi.org/10.3390/polym12010007.

10. Aslam, M., Kalyar, M.A., Raza, Z.A. Polyvinyl alcohol: A review of research status and use of polyvinyl alcohol based nanocomposites. Polym. Eng. Sci. 2018, 58, 2119-2132, https://doi.org/10.1002/pen.24855.

11. Alghoraibi, I.; Alomari, S. Different methods for nanofiber design and fabrication. In Handbook of Nanofibers. 2nd ed.; Barhoum, A., Bechelany, M., Makhlouf, A., Eds.; Springer: Cham., Germany, 2018, 3, 1-46, https://doi.org/10.1007/978-3-319-42789-8_11-2.

12. Zhang, W.; Ronca, S.; Mele, E. Electrospun nanofibres containing antimicrobial plant extracts. Nanomaterials 2017, 7, 1-17, https://doi.org/10.3390/nano7020042.

13. Sousa, E.A. O.; Neves, E. A.; Alves, C. R. Therapeutic potential of aloe vera (aloe barbadensis): a brief review Rev. Virtual Quim. 2020, 12, 378-388, http://dx.doi.org/10.21577/1984-6835.20200030.

14. Goudarzi, M.; Fazeli, M.; Azad, M.; Seyedjavadi, S.S.; Mousavi, R. Aloe vera gel: effective therapeutic agent against multidrug-resistant Pseudomonas aeruginosa isolates recovered from burn wound infections. Chemother. Res. Pract. 2015, 1-5, https://doi.org/10.1155/2015/639806.

15. Sánchez, M., González-Burgos, E., Iglesias, I., \& Gómez-Serranillos, M. P. Pharmacological update properties of aloe vera and its major active constituents. Molecules (Basel, Switzerland) 2020, 25, 1-37, https://doi.org/10.3390/molecules25061324.

16. Mehrani Sabet, J.; Gill, P. Fabrication of aloe vera nano-cellulose via mechanical method. WO Patent No. 2018104971, 2018.

17. Domingo-Calap, P.; Delgado-Martínez, J. Bacteriophages: protagonists of a post-antibiotic era. Antibiotics (Basel) 2018, 7, 1-16, https://dx.doi.org/10.3390\%2Fantibiotics7030066.

18. Loh, B.; Gondil, V.S.; Manohar, P.; Khan, F.M.; Yang, H.; Leptihn, S. Encapsulation and delivery of therapeutic phages. Appl Environ Microbiol 2021, 87, e01979-20, https://doi.org/10.1128/AEM.01979-20.

19. Can-Herrera, L.A.; Oliva, A.I.; Dzul-Cervantes, M.A.A.; Pacheco-Salazar, O.F.; Cervantes-Uc, J.M. Morphological and mechanical properties of electrospun polycaprolactone scaffolds: effect of applied voltage. Polymers 2021, 13, 1-15, https://doi.org/10.3390/polym13040662. 
20. Blachowicz, T.; Domino, K.; Koruszowic, M.; Grzybowski, J.; Böhm, T.; Ehrmann, A. Statistical Analysis of Nanofiber Mat AFM Images by Gray-Scale-Resolved Hurst Exponent Distributions. Appl. Sci. 2021, 11, 2436, https://doi.org/10.3390/app11052436.

21. Marrese, M.; Guarino, V.; Ambrosio, L. Atomic force microscopy: a powerful tool to address scaffold design in tissue engineering. J. Funct. Biomater. 2017, 8, 1-20, https://doi.org/10.3390/jfb8010007.

22. Rahimzadeh, G.; Gill, P.; Rezai, M.S. Characterization of methicillin-resistant staphylococcus aureus (mrsa) phages from sewage at a tertiary pediatric hospital. Arch. Pediatr. Infect. Dis. 2017, 5, e39615, https://dx.doi.org/10.5812/pedinfect.39615.

23. Zamani, F.; Amani-Tehran, M.; Latifi, M.; Shokrgozar, M.A. The influence of surface nanoroughness of electrospun PLGA nanofibrous scaffold on nerve cell adhesion and proliferation. J. Mater. Sci. Mater. Med. 2013, 24, 1551-1560, https://doi.org/10.1007/s10856-013-4905-6.

24. Niemczyk-Soczynska, B.; Gradys, A.; Sajkiewic, P. Hydrophilic surface functionalization of electrospun nanofibrous scaffolds in tissue engineering. Polymers 2020, 12, 1-20, http://dx.doi.org/10.3390/polym12112636.

25. Scott, H.; Mattey, M. Immobilisation and stabilisation of virus. WO Patent No. 2003093462A2, 2003.

26. Swann, H.; Sharma, A.; Preece, B.; Peterson, A.; Eldridge, C.; Belnap, D.M.; Vershinin, M.; Saffarian, S. Minimal system for assembly of SARS-CoV-2 virus like particles. Sci. Rep. 2020, 10, 1-5, https://doi.org/10.1038/s41598-020-78656-w.

27. Soothill, J.; Hawkins, C.; Harper, D.; Bacteriophage-containing therapeutic agents. US Patent No. $20070190033 A 1,2007$.

28. Górski, A.; Borysowski, J.; Miedzybrodzki, R. Phage therapy: towards a successful clinical trial. Antibiotics 2020, 9, 1-7, http://dx.doi.org/10.3390/antibiotics9110827.

29. Urban, M.W.; Elasri, M. Covalent attachment of bacteriophages (phages) to polymeric surfaces. EP Patent No. 2961482A1, 2016.

30. Chlanda, A.; Rebis, J.; Kijeńska, E.; Wozniak, M.J.; Rozniatowski, K.; Swieszkowski, W.; Kurzydlowski, K.J. Quantitative imaging of electrospun fibers by PeakForce Quantitative NanoMechanics atomic force microscopy using etched scanning probes. Micron 2015, 72, 1-7, https://doi.org/10.1016/j.micron.2015.01.005.

31. Ferraris, S.; Spriano, S.; Scalia, A.C.; Cochis, A.; Rimondini, L.; Cruz-Maya, I.; Guarino, V.; Varesano, A.; Vineis, C. Topographical and biomechanical guidance of electrospun fibers for biomedical applications. Polymers 2020, 12, 1-32, http://dx.doi.org/10.3390/polym12122896.

32. Philip, P.; Jose, E.T.; Chacko, J.K.; Philip, K.; Thomas, P. Preparation and characterisation of surface roughened PMMA electrospun nanofibers from PEO-PMMA polymer blend nanofibers. Polym. Test. 2019, 74, 257-265, https://doi.org/10.1016/j.polymertesting.2019.01.009.

33. Can-Herrera, L.A.; Oliva, A.I.; Dzul-Cervantes, M.A.A.; Pacheco-Salazar, O.F.; Cervantes-Uc, J.M. Morphological and mechanical properties of electrospun polycaprolactone scaffolds: effect of applied voltage. Polymers 2021, 13, 1-15, https://doi.org/10.3390/polym13040662.

34. Khanzada, H.; Salam, A.; Qadir, M.B.; Phan, D.N.; Hassan, T.; Munir, M.U.; Pasha, K.; Hassan, N.; Khan, M.O.; Kim, I.S.. Fabrication of promising antimicrobial aloe vera/pva electrospun nanofibers for protective clothing. Materials 2020, 13, 1-14, http://dx.doi.org/10.3390/ma13173884.

35. Maleknia, L.; Dilamian, M.; Pilehrood, M.K.; Sadeghi-Aliabadi, H.; Hekmati, A.H. Preparation, process optimization and characterization of core-shell polyurethane/chitosan nanofibers as a potential platform for bioactive scaffolds. Res. Pharm. Sci. 2018, 13, 273-282, https://doi.org/10.4103/1735-5362.228957.

36. Hikmawati, D.; Rohmadanik, A.; Putra, A. The effect of aloe vera extract variation in electrospun polyvinyl alcohol (PVA)-Aloe vera-based nanofiber membrane. J. Phys.: Conf. Ser. 2018, 1120, 1-8, https://doi.org/10.1088/1742-6596/1120/1/012096.

37. Miguel, S.P.; Ribeiro, M.P.; Coutinho, P.; Correia, I.J. Electrospun polycaprolactone/aloe vera-chitosan nanofibrous asymmetric membranes aimed for wound healing applications. Polymers 2017, 9, 1-24, https://dx.doi.org/10.3390\%2Fpolym9050183.

38. Hajian, M.; Mahmoodi, M.; Imani, R. In vitro assessment of poly (vinyl alcohol) film incorporating aloe vera for potential application as a wound dressing. J. Macromol. Sci. Phys. 2017, 56, 435-450, https://doi.org/10.1080/00222348.2017.1330183. 